\title{
BMJ Open Are schools and alcohol a good mix? A qualitative study of school principals' experiences of adults' alcohol use in Australian secondary schools
}

\author{
Bernadette M Ward, ${ }^{1}$ Penny Buykx, ${ }^{1,2}$ Geoffrey Munro, ${ }^{3}$ John Wiggers ${ }^{4}$
}

To cite: Ward BM, Buykx P, Munro G, et al. Are schools and alcohol a good mix? A qualitative study of school principals' experiences of adults' alcohol use in Australian secondary schools. BMJ Open 2016;6:e010904. doi:10.1136/bmjopen-2015010904

- Prepublication history and additional material is available. To view please visit the journal (http://dx.doi.org/ 10.1136/bmjopen-2015010904).

Received 16 December 2015 Revised 12 June 2016 Accepted 5 July 2016

CrossMark

\begin{abstract}
${ }^{1}$ School of Rural Health, Monash University, Bendigo, Victoria, Australia

${ }^{2}$ School of Health and Related Research, University of Sheffield, Sheffield, UK

${ }^{3}$ Alcohol and Drug Foundation, Melbourne, Victoria, Australia

${ }^{4}$ School of Medicine and Public Health, University of Newcastle, Australia
\end{abstract}

Correspondence to Dr Bernadette M Ward; Bernadette.ward@monash. edu

\section{ABSTRACT}

Objective: Parents, schools and the broader community influence children's socialisation to alcohol. In Australia, the UK and the USA, there have been media reports of adults consuming alcohol at familyfocused school events such as fairs and graduations. The aim of this qualitative study was to describe school principals' experiences of adults' use of alcohol at school events, when children are present.

Design/setting/participants: A qualitative study was undertaken. Publicly available lists were used to invite 60 principals from government and Catholic secondary schools in Victoria, Australia. In-depth interviews were conducted and analysed thematically and reported using the Consolidated Criteria for Reporting Qualitative Research guidelines.

Results: 14 principals ( 5 female, 9 male) participated. Most (10) of the participating principals reported adults' use of alcohol at events when students were present. Regarding these events, most principals reported concerns regarding potential harms and responsibility for decision-making about alcohol availability in schools. Some (4) principals believed alcohol should not be present at such events and this was their practice. Half of the participating schools had recently made changes to reduce the availability or management of alcohol at school functions.

Conclusions: The findings confirm the common use of alcohol by adults at school events, the challenges this poses for school principals and suggests consideration needs to be given to identifying strategies for supporting schools and school principals in decision-making regarding the conduct of such events.

\section{INTRODUCTION}

For many young people, the frequent use of alcohol is a normalised behaviour. ${ }^{1-3}$ A number of factors influence the initiation and pattern of alcohol consumption by young people. Among these, exposure to advertising is significantly associated with adolescents' early initiation and later elevated levels of

\section{Strengths and limitations of this study}

- This research addresses an emerging issue in relation to the promotion, role modelling and use of alcohol in schools.

- It is the first study to qualitatively describe the experiences, beliefs and decision-making of school principals in relation to adults' use of alcohol in schools when children are present.

- The findings confirm earlier reports of the common use of alcohol by adults in the presence of students at some school events, and the challenges principals face in managing such events.

- This was a qualitative study conducted in one state only (Victoria), so the results may not be representative of all Australian schools.

alcohol use. ${ }^{4-7}$ Similarly, parental consumption of alcohol has been reported to be significantly associated with adolescents' earlier initiation to and subsequent use of alcohol, while mothers' frequency of alcohol consumption is associated with initiation to drinking among primary school-aged children. ${ }^{8} 9$ Such modelling behaviour can occur in a number of settings, including in schools where adults consume alcohol in the presence of children. ${ }^{10} 11$

Schools are influential in educating and socialising children and are regarded as an important setting for promoting student and community well-being. ${ }^{12}$ The Health Promoting Schools framework is an accepted approach for schools to incorporate the promotion of health and well-being into all aspects of school life by focusing on (1) the curriculum, teaching and learning; (2) the school organisation, ethos and environment; and (3) partnerships with parents and community services. ${ }^{13}$ In the context of this role and framework, there is an increasing acceptance that schools need to consider their broader actions with regard to reducing the 
risks of alcohol-related harm for students, particularly with regard to the school's alcohol policies and activities relating to the use of alcohol by parents and the broader community at school events. ${ }^{14-16}$ As evidence demonstrates that schools and parents cannot rely on curriculum-based programmes alone to prevent alcohol consumption among all young people, or to prevent heavy consumption by a subset of students, ${ }^{17} 18$ a "wholeschool' approach to alcohol education is widely advocated. ${ }^{19}$

The use of alcohol by adults at school events has recently emerged as a potential point of tension between schools and broader social norm of alcohol being part of all social activity. ${ }^{10}$ For example, in 2013, alcohol was reported to have been served at 8402 primary school fetes, discos and sports events in England and Wales. ${ }^{11}$ Similarly, in a recent survey of 241 Australian secondary school principals in Victoria and New South Wales (NSW), 36\% of principals reported adults' alcohol use at graduations, debutante balls, fetes and a school camp in the previous 12 months. ${ }^{20}$ While the actual prevalence of adults' alcohol use or harms occurring in Australian schools has not been reported, there have been recent anecdotal reports of 'drunken parents', assaults of school staff ${ }^{21}$ and parents' consumption of alcohol at school sporting and fundraising events. $^{102223}$

Explicit guidance for schools and communities regarding adults' use of alcohol at school events is variable across jurisdictions and in many cases limited. In the UK for instance, the sale and supply of alcohol at school events requires a 'Temporary Event Notice' licence. ${ }^{24}$ The licence is not specific to alcohol and while there are some restrictions on the events to which the licence applies, there are no specific restrictions on alcohol use at school events. While many Australian state and territory education departments have policies/guidelines regarding alcohol consumption at schools more broadly, most lack specificity regarding the principles and processes for determining adults' use of alcohol at school events when students are present. ${ }^{25}$ In addition, responsibility for decisions regarding adult consumption of alcohol at school events lies primarily with school principals and/or school councils in most Australian states and territories. ${ }^{25}$

Limited data have been reported regarding the beliefs and decision-making needs of school principals with regard to adult consumption of alcohol during school events. In a survey of 218 Australian secondary school principals, participants reported that the alcohol 'culture' and associated negative role modelling of some parents need to be addressed. ${ }^{26}$ In the context of such challenges, principals reported a need to engage with parents and communities. ${ }^{26}$ While adults' use of alcohol at school events is significantly associated with principals' need for further information on this issue, ${ }^{20}$ there is a dearth of research regarding the type of information and support that school principals require in their development of school policies and in making decisions about adults' use of alcohol at school events. To address this gap, a qualitative study was undertaken to describe school principals' experiences of adults' use of alcohol at school events, when children are present.

\section{METHODS}

\section{Study design, setting and sample}

Given the lack of published research addressing the study aims, a qualitative study was undertaken. ${ }^{27}$

The study was conducted in Victoria, Australia. In Victoria, after ensuring the "legal requirements for the sale and/or provision of alcohol in public situations at school functions are enforced', ${ }^{28}$ responsibility for decisions regarding if, how and when adults can consume alcohol at school events rests with the principal and school council. ${ }^{28}$ The prevalence of school events in which adults consume alcohol is higher in Victoria than in NSW. ${ }^{20}$

There are 339 dedicated secondary schools in Victoria: $239(71 \%)$ are government schools, $85(25 \%)$ are Catholic and $15(4 \%)$ are independent schools. ${ }^{29}$ Purposive sampling was used to select schools based on school type and size, location and Index of Community Socio-Educational Advantage (ICSEA) ${ }^{30}$ Schools were excluded if they did not include year 7-12 classes; were in remote areas; had ICSEA scores that indicated socioeconomic disadvantage $(<900)$ or advantage $(>1300)$; and/or had $<500$ or $>1500$ students enrolled. In 2014, using publicly available lists of schools, 40 (17\%) government and 20 (24\%) Catholic secondary school principals were iteratively invited by mail to participate in the study. Each invitation was followed up with two telephone call/ emails to ascertain principals' interest in participating. Principals who were interested in participating were sent the interview schedule. Principals provided written consent. Concurrent data collection and recruitment continued until data saturation was reached. ${ }^{31}$

\section{Data collection and analysis}

Principals were asked to participate in semistructured, 45-90 min recorded interviews either at their school or via the telephone as preferred by them. The interview schedule was structured according to the Health Promoting Schools model with an emphasis on items addressing the school organisation; ethos and environment; and partnerships with parents and local communities. $^{13}$ The interview items were informed by previous studies. ${ }^{10}$ Following pretesting and feedback, the schedule was modified (see online supplementary appendix 1). The data were collected by BMW and JS (a research assistant) who have experience in qualitative interviewing. The data were transcribed verbatim and participants were offered a copy of their transcript for checking. The data were managed in NVivo (NVivo qualitative data analysis software [program]. Version 10, 2012 version: QSR International Pty. 2012). Two 
researchers with qualitative analysis experience (BMW and $\mathrm{PB}$ ) independently read, reread and thematically coded the transcripts and field notes. Preliminary open coding was used to derive themes from the data and inform ongoing data collection. ${ }^{31}$ Memos, field notes and visual representations of the data were used to facilitate team discussions and review of the emerging themes and subthemes. ${ }^{31}{ }^{32}$ The Consolidated Criteria for Reporting Qualitative Research (COREQ) guidelines were used to guide the reporting of the study. ${ }^{33}$

\section{Ethics approval}

The study was approved by the Victorian Department of Education and Training, Catholic Education, University of Newcastle, Australian Drug Foundation and Monash University Human Research Ethics Committees.

\section{RESULTS}

\section{Participants}

A total of 14 school principals participated from the 60 schools iteratively contacted: 5 Catholic and 9 government secondary schools. Seven of the principals were in major cities and seven were in rural locations.

\section{Thematic findings}

Four key themes emerged from the data: the use of alcohol at school events; beliefs about alcohol use in schools; decision-making; and change in policy and practice. A summary of the analysis is provided in figure 1, and each theme and subtheme is described below and illustrated with direct quotes from participants.

\section{The use of alcohol at secondary school events}

Several (4) principals reported no use of alcohol at school events when students were present. Most (10) principals reported that adults used alcohol at school events in the past 12 months. The types (10) and frequency of events (1-40/year) varied and included debutante/presentation balls, graduation/valedictory dinners, musicals, art shows, sports events, fundraisers, opening of school buildings, cocktail parties, international excursions and staff/school council/board meetings (where students attended or were able to see adults drinking alcohol).

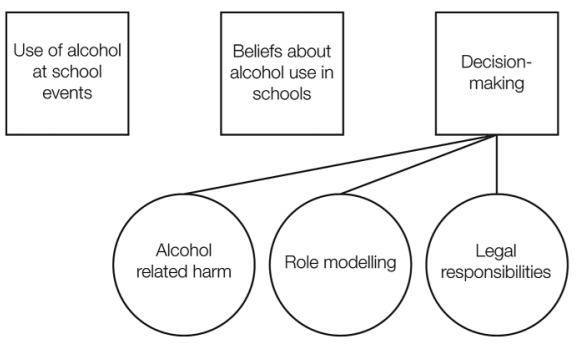

We wanted to celebrate so we thought we'd just give the parents a glass of champagne...to celebrate the opening of the .... (Major city, Catholic, principal 6)

Events involving alcohol that included formal meals were generally held at off-school locations at licensed venues, while fundraisers, shows and school welcoming/ opening events were most frequently held at school. In some cases, alcohol was supplied or sold by the school and in other cases, parents took their own supply (bring your own). Of the events where alcohol was consumed, some were primarily focused on students (eg, school musical), while others were focused on parents (eg, weekend sporting event for old collegians, school council/board meetings) and staff (meetings or Friday night 'drinks' in the staff room).

\section{Beliefs about alcohol use in schools}

Beliefs about the role of alcohol in secondary schools ranged from 'there's no place for alcohol in a school environment' to 'alcohol is just...part of the furniture'. Several (4) principals believed alcohol should not be available for adults when students were present, with their schools holding alcohol-free events as a consequence. An additional eight principals expressed similar beliefs, but indicated that alcohol was available for adults at such events. This dissonance was linked to historical and cultural practices in the school. For example:

There's no RSL ...no hotels in the area...they've probably just been doing it [drinking at school] for 20 years...and that's just part of the culture really. (Major city, government, principal 12)

A couple (2) of principals reported that they were comfortable with adults' consuming alcohol at these occasions.

If you've got presentation nights... and adults want to have a drink...I don't have an issue with it personally and the school per se doesn't. So we're relatively liberal in that regard. (Major city, Catholic, principal 2)

A few (3) principals expressed concern about the availability of alcohol at secondary school events and the risk this posed in terms of encouraging older students to consume alcohol at school. In this context, two principals believed alcohol use in primary schools was less problematic.

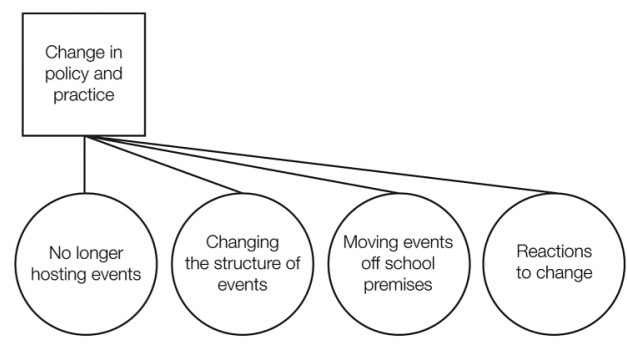

Figure 1 Summary of themes and subthemes. 
If you're having a year 7 function and a parent function it's a lot easier than if you've got a year 11-12 where some of those students might be 18 , whereas at primary school you don't have any of those distinctions. (Major city, Catholic, principal 3)

\section{Decision-making}

All principals reported that they had responsibility for decision-making about alcohol use at school events. Most school principals were aware that they had discretion about adults' use of alcohol at school events, but six suggested it would be easier for them if all events where students were present were alcohol free. One principal said:

Good schools are a reflection of the community that they work in and they need to, in many cases, set the example. (Major city, government, principal 13)

Half (7) of the principals reported that they had a role in educating staff and school council members regarding the use of alcohol by adults at school events. Some (5) principals reported they used 'common sense' when making these decisions and while six suggested there was probably information online to assist, none of the interviewed principals indicated that they had referred to the education department guidelines.

Principals framed their decision-making regarding the consumption of alcohol by adults in the presence of students around three considerations: the potential for alcohol-related harms; role modelling; and legal responsibilities.

\section{Alcohol-related harm}

All principals perceived the potential for alcohol-related harms arising from alcohol being consumed by adults at a school event. Six principals reported having experienced such harms at a school event. For example:

I've been in schools where there has been alcohol used at functions and I've just seen so many disasters. I've been at debutante balls at other schools where [the students] were having boat races [drinking games] at the bar with [school] staff. (Major city, government, principal 8)

As a consequence of these experiences, the six principals reported the experience had influenced them to modify and/or discontinue alcohol use and/or such events.

In contrast, all principals who had not experienced alcohol-related harm as a result of adult drinking at a school event said that they would review the policy if there was any violence. One of these principals expressed a more permissive attitude towards alcohol at such events and believed that responsibility lay with the parents, not the school.
We don't formally do anything around telling kids who are under 18 that they can't drink at that [school] function-that's a matter for their parents. (Major city, Catholic, principal 2)

\section{Role modelling}

In explaining their stance on the consumption of alcohol by adults in the presence of students, the notion of role modelling was adopted as a basis for decisionmaking by schools which permitted adult alcohol consumption and schools which did not. Where alcohol was allowed, principals indicated that it was important for students to be exposed to 'responsible' alcohol use.

I think it is perfectly appropriate for adults to model appropriate use of alcohol in front of secondary school students. So when there are formal functions involving students and parents and staff, I have no issues with staff [and parents] consuming alcohol at those functions. (Major city, Catholic, principal 2)

In contrast, some principals expressed concern about negative role modelling of alcohol use to students and on this basis decided that school events should be alcohol free.

Alcohol can be consumed in a responsible way-does that mean you have to? (Rural, government, principal 4)

\section{Legal responsibilities}

All participants indicated awareness of the legal age of purchasing alcohol. Two principals who did not permit alcohol at any event where students were present expressed concerns about the risks being taken by other principals in allowing alcohol use at such events: " They need to understand the burden [risk] they're carrying." (Major city, government, principal 1).

\section{Change in policy and practice}

Half the principals reported making changes to alcohol policies in recent years, and the others had not.

There are a number of Catholic schools who have their things like our presentations ball, valedictorian, as dry events. That's not a pathway we've chosen to go down at this stage. (Major city, Catholic, principal 3)

In half the schools where alcohol consumption policy and practice had changed, the changes included no longer hosting events and/or allowing alcohol, or changing the structure of the event and/or moving the event off school premises. These changes were met with a range of responses from staff, school council members and parents.

\section{Schools no longer hosting events and/or allowing alcohol}

There were a variety of examples of changes in policy regarding the availability of alcohol at school events, and the number of events that schools hosted. 
We received a death threat from a bloke who said "I want a drink and you're not stopping me." But the bar was told they weren't allowed to serve it. But it got ugly in the end. We stopped running deb balls. (Rural, government, principal 10)

This is what's happening in many schools nowadays. We run that as our only official school sanctioned formal. Our year 10, 11 and 12 students in most years have organised a formal with the support of parents. We've removed ourselves from the responsibility around that. (Rural, government, principal 4)

\section{Changing the structure of the event}

It used to be a meal with alcohol, with bottles on the table...now it's finger food after function... and the function runs for an... hour and a half so there isn't any opportunity for any excessive using of alcohol. (Major city, government, principal 1)

The same principal reported a reduction in alcoholrelated risk when the availability of alcohol was ceased or reduced.

We no longer get the friend "hangers on" who are coming to drinks. ...you get the people who genuinely want to be there to support the students. You don't get their brother and their brother's mates who are coming along for a good booze up. So ticket sales are down but they are down for the people they were always trying to restrict. (Major city, government, principal 1)

\section{Moving events off school premises}

Some (6) principals reported holding school events off school premises. Generally, this meant moving to licensed premises:

It's up to the place where we're holding the event, that's their responsibility and to police that because they are the ones that have the liquor licence, not us. (Major city, Catholic, principal 3)

However, the move to licensed premises did not necessarily reduce drinking:

...this year we're going into the city so from the time they [the parents] leave the church ...there's not much time there free for them to actually go to a bar. The only way they could actually drink is to have the esky in the boot. ...they really won't even be able to get out of the venue. Once they're in there, with the security guards... they just won't have that opportunity. (Rural, Catholic, principal 7)

\section{Staff, school council members and parents' reactions to change}

Several (4) principals told of concerns expressed by staff, school council members and parents about changes to alcohol policies; and reducing the availability and use of alcohol by adults at school events. The range of expectations that staff had regarding the use of alcohol is best described as follows:

There were a group who just really didn't like it [consumption of alcohol at school events], so they were quite happy that it had gone, anyway. Then there was another group, who sort of were happy with the story that I wasn't prepared to run the duty of care stuff .... And then the third group that said this is all just garbage and you're actually denying us a basic human right. (Major city, government, principal 12).

The same principal reported concerns from school council members and parents:

It was going to be a disaster and no one would want to make their deb because there's no alcohol there, and all this sort of stuff...they also said... "if there's not grog, no one will dance." And I said, "oh well that's bad luck too then, isn't it?" And, of course, none of those things happened, people still dance, people do all that. (Major city, government, principal 12)

\section{DISCUSSION}

This is the first study to qualitatively explore the beliefs and decision-making processes of school principals underlying the use of alcohol by adults at school events. Our findings confirm earlier reports ${ }^{10}{ }^{20}$ of adults' use of alcohol in the presence of students at some secondary school events, with 10 of 14 principals reporting such a practice. The most common of these events were those that involved student 'milestones'; celebratory occasions which mark a rite of passage or increasing maturation, such as a debutante ball or a graduation/valedictory dinner. Accounts of alcohol use by adults in the presence of students at more routinely scheduled activities (eg, at sports events or in the staff room) account for the wide range of the frequency of these type of events, but these were only reported in two schools. These findings are consistent with media reports across Australia $^{21} 22$ and may reflect the cultural imperative of drinking alcohol at Australian social events. ${ }^{34}$ Alcohol consumption at school events was seen by some principals to reinforce the perception that alcohol is a 'usual' or 'necessary' component of any gathering of adults.

The promotion and role modelling of alcohol use at school events was seen to be at odds with the principles of the Health Promoting Schools model ${ }^{13}$ by half principals. Such contradictions and concerns regarding legal and duty of care responsibilities resulted in the modification of school policy and practice by holding school events on licensed premises or ceasing/reducing the availability of alcohol. The principals who reported changing the location of school events to licensed premises said such premises were attractive because the responsibility for serving alcohol was shifted to the licensee and thus presented less risk for the school. However, three principals did not consider this approach eliminated such problems and considered such events had 
the potential to exacerbate the potential for risky problematic drinking, related harm and unsafe school events.

Changes implemented to the availability of alcohol by principals in this study were met with some resistance by staff and parents. However, the acceptability of the implementation of additional liquor restrictions and tobacco controls in the broader community is generally higher once people experience the benefits of such changes and if such changes are in the interests of children. $^{35}$ For example, public and industry support for banning alcohol within the vicinity of a school is much higher than support for a universal ban on alcohol advertising. ${ }^{35-37}$ Given this, it is possible that acceptability of changes to the availability of alcohol at school events will have broad community support. ${ }^{23}$

Adult role modelling of the use of alcohol at school functions when students are present may not be in the best interest of students or school principals. Evidence of students being exposed to short-term alcohol-related harm at school events was provided by six principals and this is consistent with previous reports. ${ }^{10}$ Students may also be exposed to negative role modelling at these events. Only four principals reported concerns about such a risk to students. There is a growing body of evidence regarding the adverse effects of alcohol on the developing adolescent brain and the cumulative effect of increased exposure to and role modelling of alcohol use on young people's earlier initiation to and subsequent drinking in adult life. ${ }^{8}{ }^{38-40}$ While parents can role model low-risk drinking at home, Australian guidelines suggest that children not be exposed to the promotion of alcohol at any school fundraising activity. ${ }^{16}$

The results of this study suggest that principals are exposing schools to additional regulatory responsibilities through their support of adults' use of alcohol at school events. In Victoria, Australia and in the UK, much of the decision-making on this issue to the discretion of the school principal and council. ${ }^{24} 28$ The extent to which the burden of risk associated with supporting adults' use of alcohol at school events outweighs any benefits of the practice does not appear to have been identified in UK or Australian government licencing/policy guidelines.

The study findings are consistent with previous reports of principals' recognition that school leaders have a role in contributing to changing the alcohol culture in the Australian community generally. ${ }^{26}$ However, the findings of this study suggest that the operationalisation of this within a Health Promoting Schools model can be challenging for principals. As one principal reported, "You can't control parents at a school function." Such a view demonstrates the challenge for principals of needing to balance the curriculum and duty of care obligations of the school with the need to involve community members in school activities. Such a challenge has been reported to impede school implementation of other health initiatives, ${ }^{41}$ such as the types of food served at school-related functions. ${ }^{42}$
This qualitative study was limited to principals in Victorian government and Catholic secondary schools, so the findings may not be generalisable to settings outside this context. We do not know the reasons principals declined our invitation to participate. Participation may have reflected a social desirability bias by principals who perceive their school is performing well on this issue. While there is evidence that the majority of parents disagree with the use of alcohol at Australian school events, ${ }^{23}$ further research is needed to explore what (if anything) principals are doing to manage their legal and educative responsibilities regarding adults' use of alcohol at school events and how this might differ across geographical location, school sector (government, Catholic and independent/private), size and socioeconomic setting.

\section{CONCLUSIONS}

This research addresses an emerging issue in relation to the promotion and role modelling of the use of alcohol at school events, and the challenges and needs of school principals in decision-making regarding such events. The findings suggest consideration needs to be given to identifying strategies for supporting schools and school principals in decision-making regarding the conduct of such events.

Acknowledgements The authors wish to thank the principals who participated in the study and Julie Symons who assisted with some of the data collection.

Contributors BMW, PB, GM and JW conceived the study. All authors participated in its design and coordination. BMW and PB performed the qualitative analysis. All authors read and approved the final manuscript.

Funding Funding for the study was provided by Victorian Health Promotion Foundation (20338).

Competing interests None declared

Ethics approval Victorian DE\&T, Catholic Education, University of Newcastle, Australian Drug Foundation and Monash University Human Research Ethics Committees.

Provenance and peer review Not commissioned; externally peer reviewed.

Data sharing statement The qualitative interview transcripts are identifiable and so are not available.

Open Access This is an Open Access article distributed in accordance with the Creative Commons Attribution Non Commercial (CC BY-NC 4.0) license, which permits others to distribute, remix, adapt, build upon this work noncommercially, and license their derivative works on different terms, provided the original work is properly cited and the use is non-commercial. See: http:// creativecommons.org/licenses/by-nc/4.0/

\section{REFERENCES}

1. Pennay A, Lubman DI. Alcohol and energy drinks: a pilot study exploring patterns of consumption, social contexts, benefits and harms. BMC Res Notes 2012;5:369.

2. Nicholls J. Everyday, everywhere: alcohol marketing and social media--current trends. Alcohol Alcohol 2012;47:486-93.

3. Cavazos-Rehg PA, Krauss MJ, Sowles SJ, et al. "Hey Everyone, I'm Drunk." An evaluation of drinking-related twitter chatter. J Stud Alcohol Drugs 2015;76:635-43.

4. Smith LA, Foxcroft DR. The effect of alcohol advertising, marketing and portrayal on drinking behaviour in young people: systematic review of prospective cohort studies. BMC Public Health 2009;9:51. 
5. Jones SC, Magee CA. Exposure to alcohol advertising and alcohol consumption among Australian adolescents. Alcohol Alcohol 2011;46:630-7.

6. Pasch KE, Komro KA, Perry CL, et al. Outdoor alcohol advertising near schools: what does it advertise and how is it related to intentions and use of alcohol among young adolescents? J Stud Alcohol Drugs 2007;68:587-96.

7. Pettigrew S, Roberts M, Pescud M, et al. The extent and nature of alcohol advertising on Australian television. Drug Alcohol Rev 2012;31:797-802.

8. Ryan SM, Jorm AF, Lubman DI. Parenting factors associated with reduced adolescent alcohol use: a systematic review of longitudinal studies. Aust N Z J Psychiatry 2010;44:774-83.

9. Ennett ST, Jackson C, Bowling JM, et al. Parental socialization and children's susceptibility to alcohol use initiation. J Stud Alcohol Drugs 2013;74:694-702.

10. Munro G, Buykx P, Ward B, et al. Adult drinking in Australian schools. Aust N Z J Public Health 2014;38:205-8.

11. Boffey D. Call to stop alcohol at primary school events The Observer, 2014. http://www.theguardian.com/society/2014/mar/08/ ban-alcohol-primary-school-events-swanswell

12. Stewart-Brown S. What is the evidence on school health promotion in improving health or preventing disease and, specifically, what is the effectiveness of the health promoting schools approach?. Health Evidence Network report. Copenhagen: WHO Regional Office for Europe, 2006.

13. Australian Health Promoting Schools Association. A national framework for health promoting schools (2000-2003), 2000. http:// www.ahpsa.org.au/

14. Sancassiani F, Pintus E, Holte A, et al. Enhancing the emotional and social skills of the youth to promote their wellbeing and positive development: a systematic review of universal school-based randomized controlled Trials. Clin Pract Epidemiol Ment Health 2015;11(Suppl 1):21-40.

15. Meyer L, Cahill H. Principles for school drug education. Canberra: Australian Government Department of Education, Science and Training, 2004

16. Australian National Council on Drugs (ANCD). School fundraising and alcohol. Canberra: ANCD, 2011. http://www.atoda.org.au/ wp-content/uploads/SchoolFundraisingAlcohol.pdf

17. Teesson M, Newton NC, Barrett EL. Australian school-based prevention programs for alcohol and other drugs: a systematic review. Drug Alcohol Rev 2012;31:731-6.

18. Lee N, Cameron J, Battam S, et al. Alcohol education for Australian schools: A review of the evidence. Adelaide: National Centre for Education and Training on Addiction, 2014.

19. National Institute for Health and Clinical Excellence (NICE). Alcohol: school-based interventions. London: NICE, 2007. https://www.nice. org.uk/guidance/ph7/chapter/1-Recommendations

20. Ward BM, Kippen R, Buykx P, et al. Principals' reports of adults' alcohol use in Australian secondary schools. BMC Public Health 2016;16:195.

21. Critchley C. A beer in there. The Herald Sun 20134 August, Weekend Magazine, p.41, News Corporation.

22. Hiatt B, King R. Alcohol ban at school sports. The West Australian, 2013. https://au.news.yahoo.com/thewest/a/16163227/ alcohol-ban-at-school-sports/

23. Ward B, Kippen R, Buykx P, et al. Parents' level of support for adults' purchase and consumption of alcohol at primary school events when children are present. Drug Alcohol Rev 2015;34:202-6.
24. Government of the United Kingdom. Temporary Events Notice (England and Wales), Updated 22 June 2015. https://www.gov.uk/ temporary-events-notice

25. Ward BM, Buykx P, Munro G, et al. Review of policies and guidelines concerning alcohol consumption and promotion in Australian government schools. Health Promot $J$ Austr 2014;25:125-8.

26. John K See Consulting. Survey of secondary school principals on the use of alcohol and other drugs in schools. Australian National Council on Drugs (ANCD), 2013. http://www.atoda.org.au/ wp-content/uploads/rp26-survey-of-school-principals.pdf

27. Sandelowski M. Whatever happened to qualitative description? Res Nurs Health 2000;23:334-0.

28. Department of Education and Training. Alcohol Melbourne: Victorian Government 2014 [updated March 2016]. http://www.education.vic. gov.au/school/principals/spag/safety/Pages/alcohol.aspx

29. Department of Education and Training. Summary Statistics for Victorian Schools Melbourne Victorian State Government 2014. http://www.education.vic.gov.au/about/department/pages/ factsandfigures.aspx

30. Australian Curriculum Assessment and REporting Authority (ACARA). My School. ACARA, 2013. http://www.myschool.edu.au/ AboutUs/Glossary/glossaryLink

31. Liamputtong P, Ezzy D. Qualitative research methods. South Melbourne: Oxford University Press, 2005

32. Charmaz K. Grounded theory: objectivist and constructivist methods In: Denzin N, Lincoln Y, eds. Strategies of qualitative enquiry. California: Sage, 2000:249-91.

33. Tong A, Sainsbury P, Craig J. Consolidated criteria for reporting qualitative research (COREQ): a 32-item checklist for interviews and focus groups. Int J Qual Health Care 2007;19:349-57.

34. Australian National Council on Drugs (ANCD). Alcohol action plan. Canberra: ANCD, 2013. http://www.atoda.org.au/wp-content/ uploads/AlcoholActionPlan.pdf

35. Tobin C, Moodie AR, Livingstone C. A review of public opinion towards alcohol controls in Australia. BMC Public Health 2011;11:58.

36. Outdoor Media Association (OMA). Alcohol advertising guidelines. Sydney: OMA, 2013. http://oma.org.au/_data/assets/pdf_file/0019/ 6094/OMA Alcohol Guidelines 2013.pdf

37. VicHealth. Alcohol CATI component of the 2009 VicHealth Community Attitudes Survey Melbourne unpublished data, 2009.

38. Anderson P, de Bruijn A, Angus K, et al. Impact of alcohol advertising and media exposure on adolescent alcohol use: a systematic review of longitudinal studies. Alcohol Alcohol 2009;44:229-43.

39. Wetherill R, Tapert SF. Adolescent brain development, substance use, and psychotherapeutic change. Psychol Addict Behav 2013;27:393-402

40. Alcohol Concern. Creating customers: finding new ways and places to sell alcohol, and new people to buy it. Cardiff, 2014. http:// alcoholireland.ie/download/reports/alcohol_marketing/ creating-customers.pdf

41. Downs SM, Farmer A, Quintanilha M, et al. From paper to practice: barriers to adopting nutrition guidelines in Schools. J Nutr Educ Behav 2012;44:114-22.

42. Dick M, Lee A, Bright M, et al. Evaluation of implementation of a healthy food and drink supply strategy throughout the whole school environment in Queensland state schools, Australia. Eur J Clin Nutr 2012;66:1124-9. 